Supporting Information for:

\title{
Multi-Cation Side Chain Anion Exchange Membranes
}

Liang Zhu ${ }^{\dagger}$, Jing Pan ${ }^{\dagger}$, Ying Wang ${ }^{\ddagger}$, Juanjuan $\operatorname{Han}^{\ddagger}$, Lin Zhuang ${ }^{\ddagger}$, and Michael A. Hickner*,

† Department of Materials Science and Engineering, The Pennsylvania State University, University Park, PA 16802, USA

* College of Chemistry and Molecular Sciences, Hubei Key Lab of Electrochemical Power Sources, Wuhan University, Wuhan 430072, China

hickner@matse.psu.edu 
Shown in Figure S1, Figure S2, Figure S3, and Figure S4 are ${ }^{1} \mathrm{H}$ NMR spectra of $1-\left(N^{\prime}, N^{\prime}-\right.$ dimethylamino)-6-( $N, N, N$-trimethylammonium) dodecane bromide in $\mathrm{CHCl}_{3}-d_{1}$, 1-(N',N'dimethylamino)-6,11-(N,N,N-trimethylammonium) undecane bromide in $\mathrm{CHCl}_{3}-d_{1}$, D40NC6NC6 in bromide salt form in DMSO- $d_{6}$, and T30NC6NC5N in bromide salt form in DMSO- $d_{6}$.

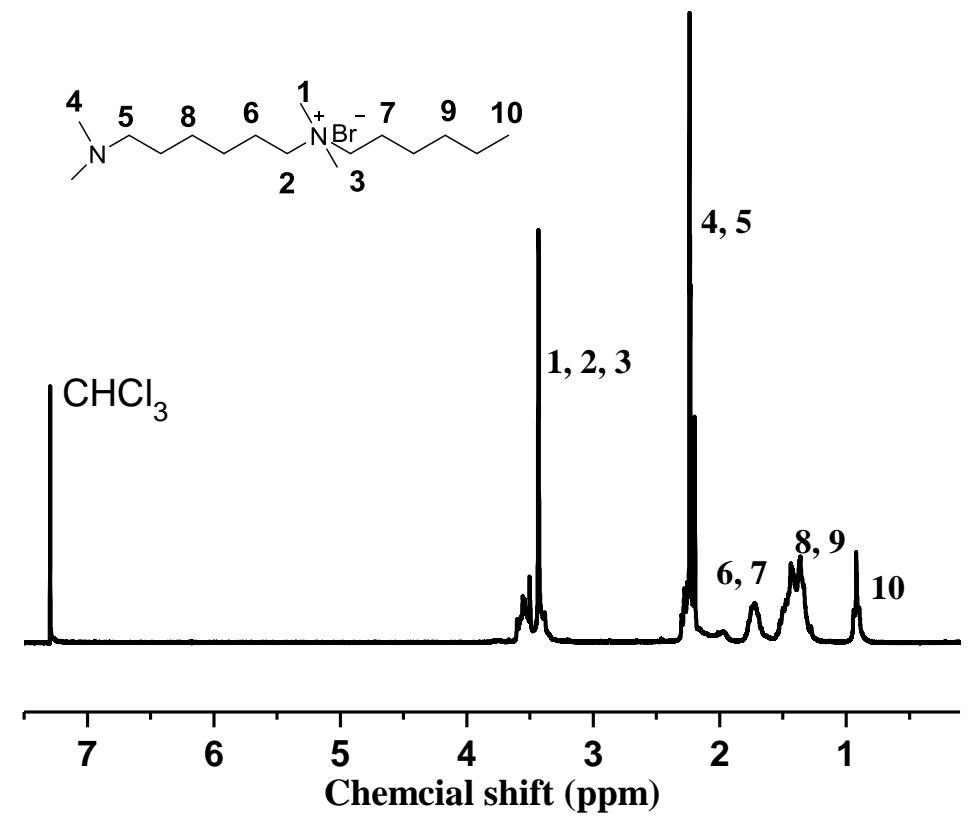

Figure S1. ${ }^{1} \mathrm{H}$ NMR of 1 -( $\left(N^{\prime}, N\right.$ '-dimethylamino)-6-( $N, N, N$-trimethylammonium) dodecane bromide in $\mathrm{CHCl}_{3}-d_{1}$. 


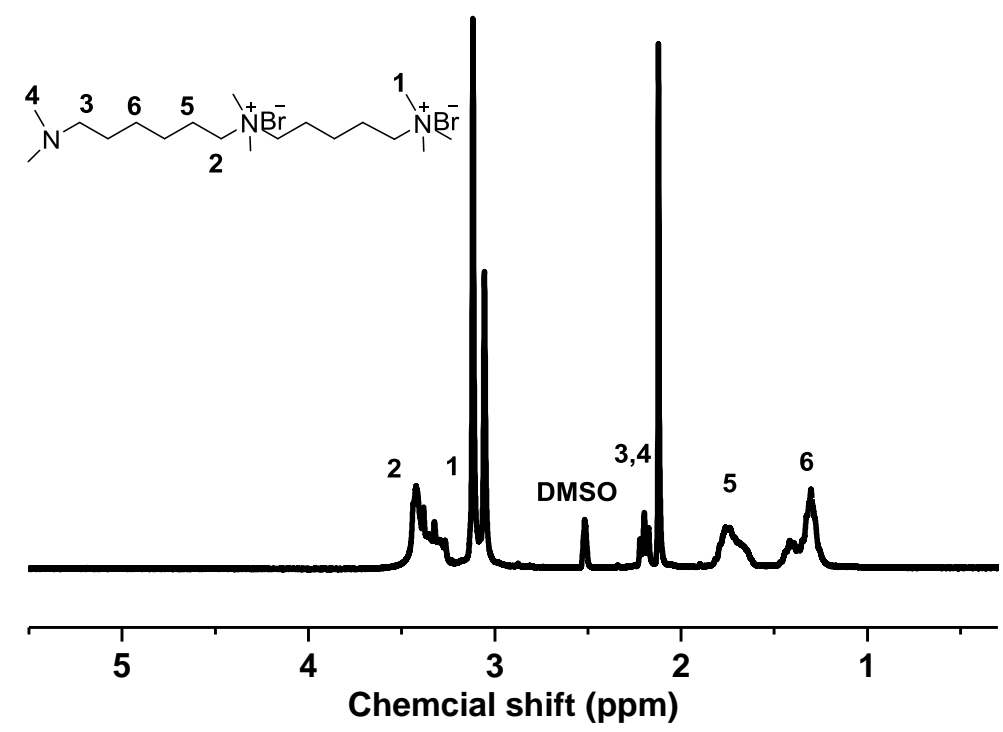

Figure S2. ${ }^{1} \mathrm{H}$ NMR of 1-( $N^{\prime}, N^{\prime}$ - dimethylamino)-6,11-( $N, N, N$-trimethylammonium) undecane bromide in $\mathrm{CHCl}_{3}-d_{1}$. 


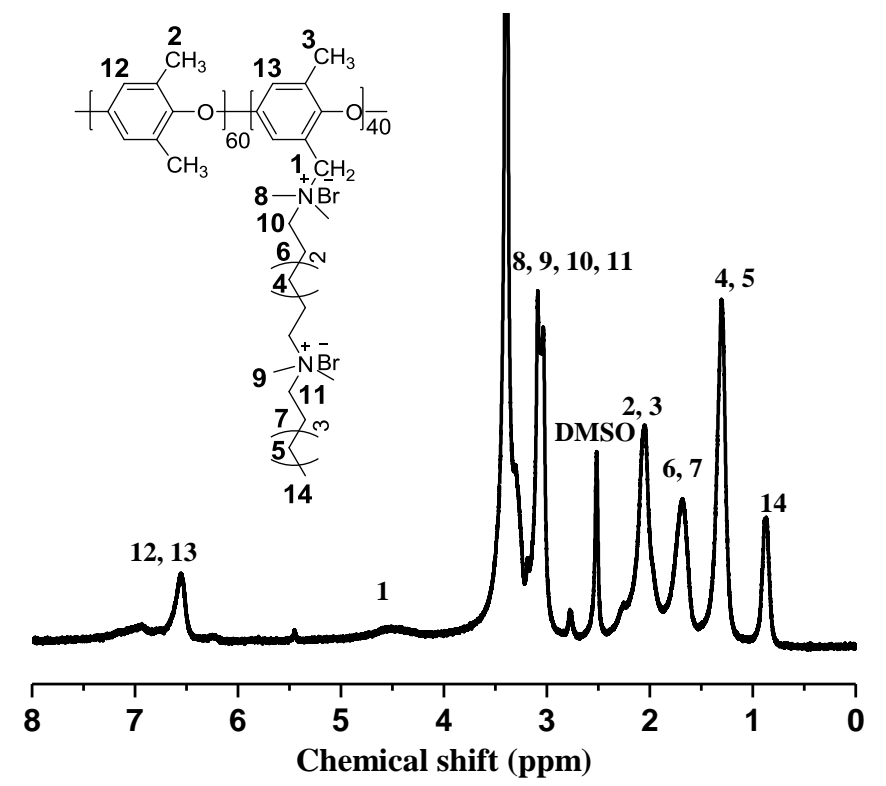

Figure S3. ${ }^{1} \mathrm{H}$ NMR of D40NC6NC6 in bromide salt form in DMSO- $d_{6}$.

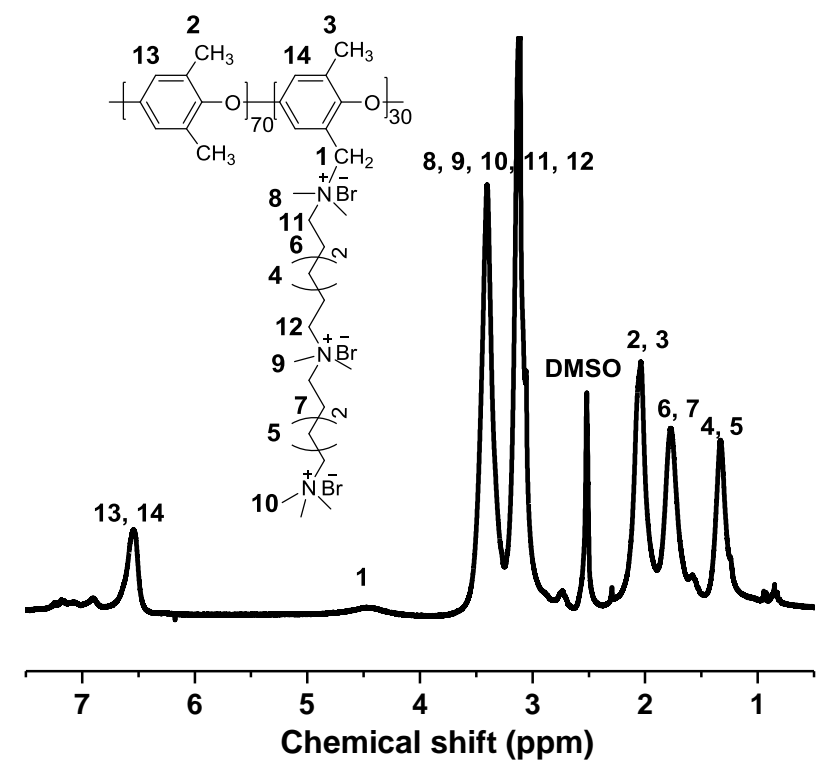

Figure S4. ${ }^{1} \mathrm{H}$ NMR of T30NC6NC5N in bromide salt form in DMSO- $d_{6}$. 
Shown in Figure S5 is the hydroxide conductivity of the AEM samples as a function of temperature.

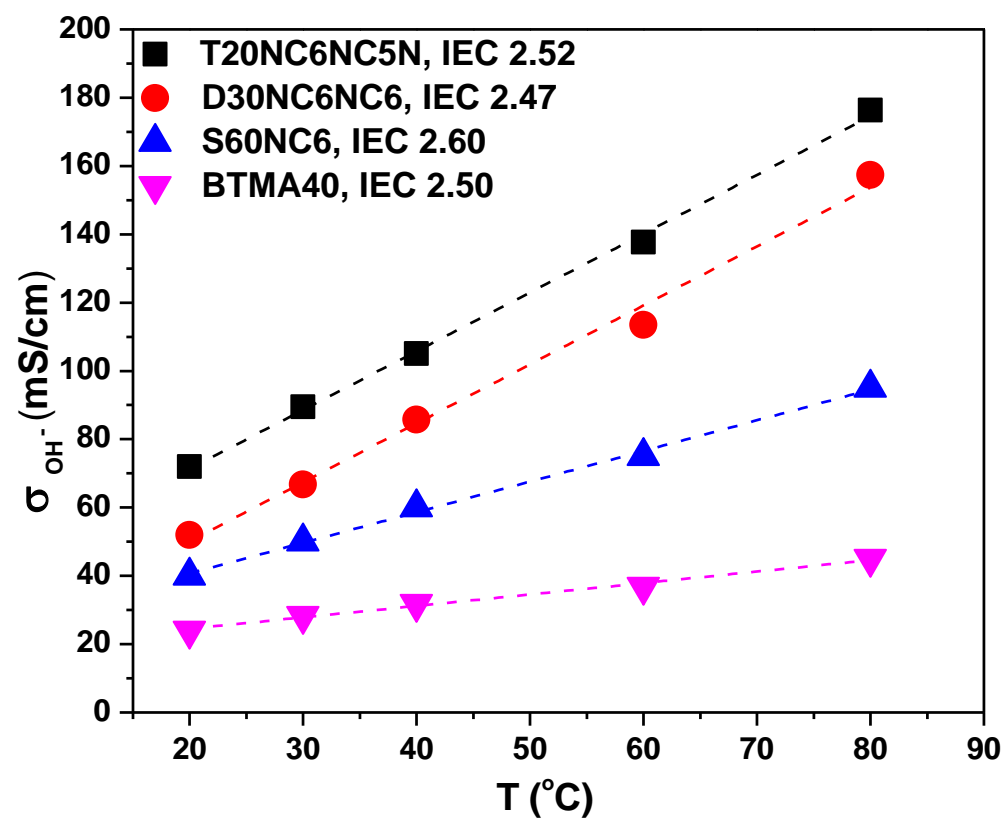

Figure S5. Hydroxide conductivity of AEMs as a function of temperature. 
Figure S6 shows hydroxide conductivity of AEMs in an Arrhenius-type temperature plot with activation energies in $\mathrm{kJ} / \mathrm{mol}$.

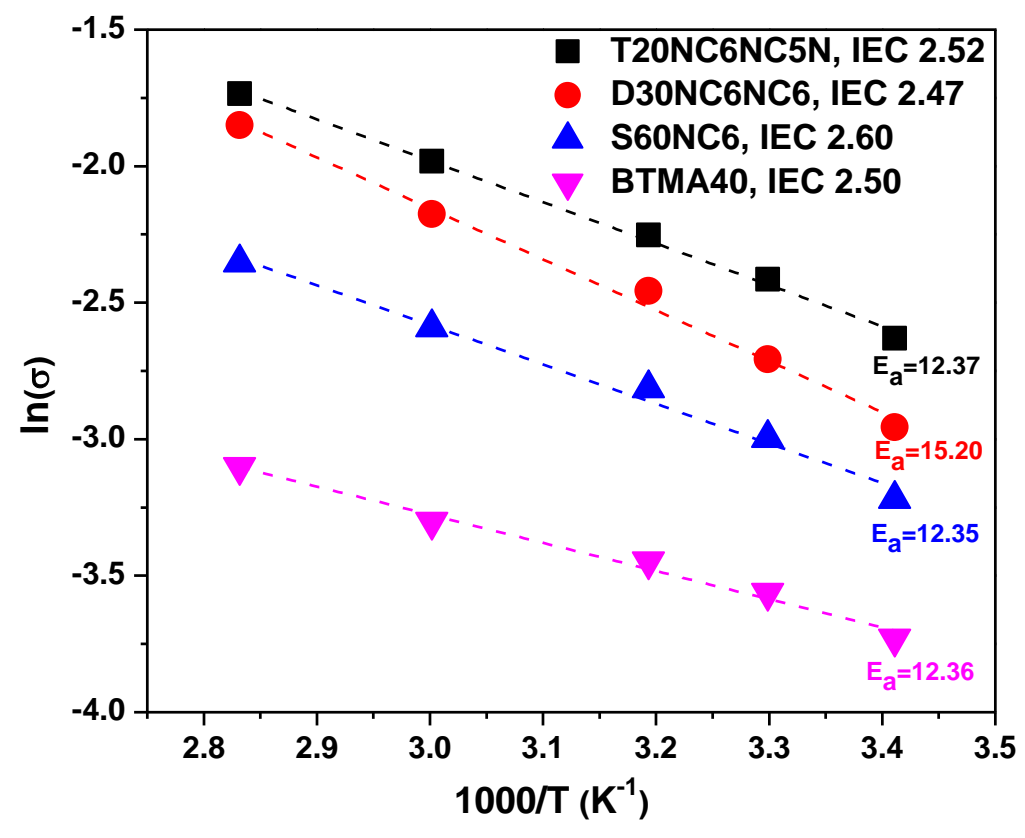

Figure S6. Hydroxide conductivity of AEMs in an Arrhenius-type temperature plot showing activation energies in $\mathrm{kJ} / \mathrm{mol}$. 
Figure S7 shows the SAXS profiles of triple-cation AEMs with increasing IEC and BTMA40 in the bromide form.

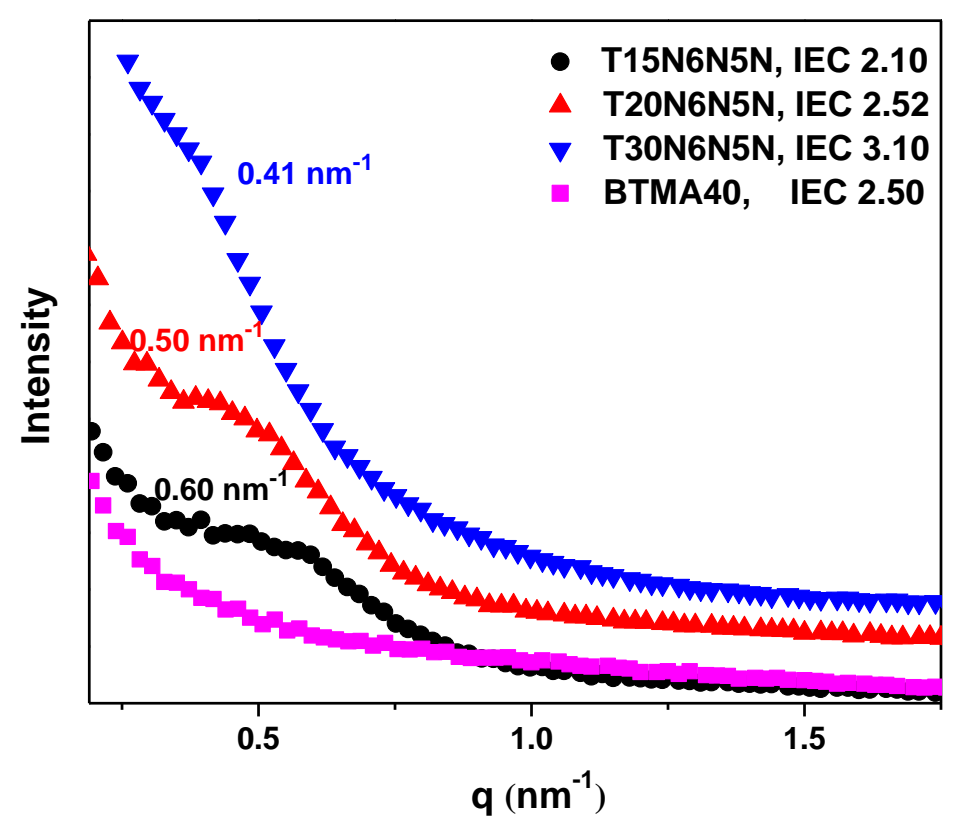

Figure S7. SAXS profiles of triple-cation and BTMA40 AEMs in the bromide form. 
Figure S8 displays water volume fraction dependence of the effective hydroxide conductivity in the water channels $\left(\sigma^{\prime}\right)$ in water at room temperature.

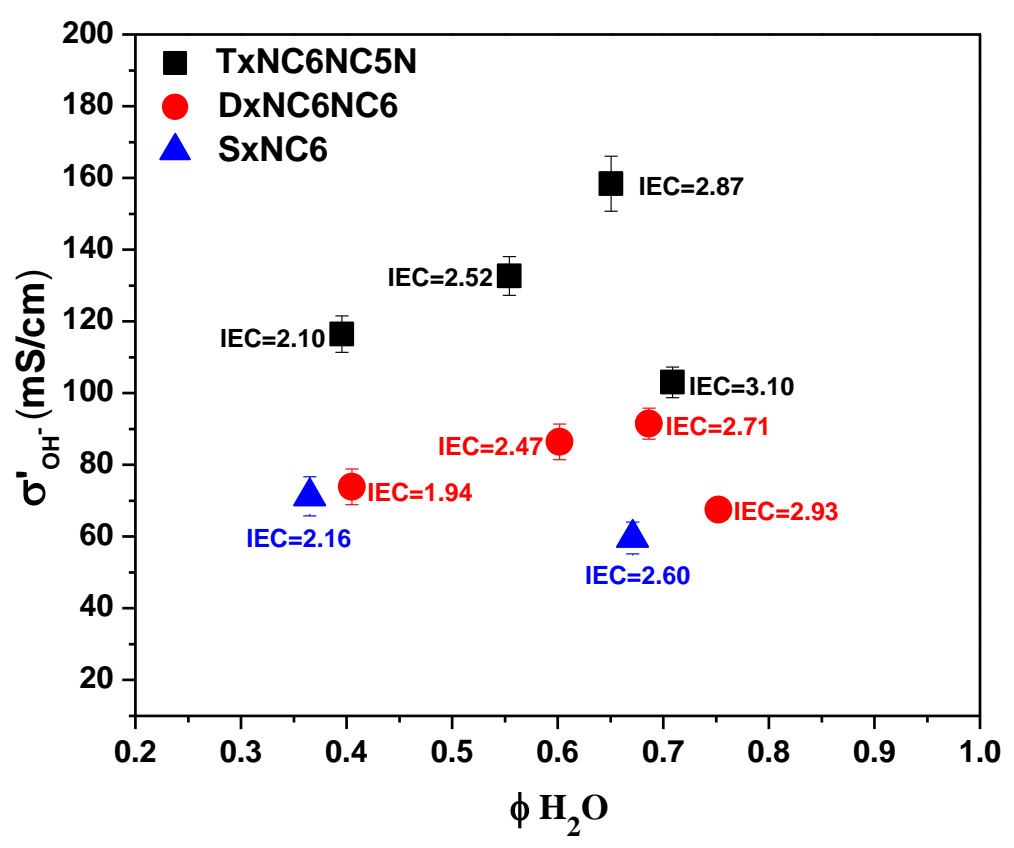

Figure S8. Water volume fraction dependence of the effective hydroxide conductivity in the water channels $\left(\sigma^{\prime}\right)$ in liquid water at room temperature. 
Figure $\mathrm{S} 9$ is $\mathrm{OH}^{-}$mobilities $\left(D / D_{0}\right)$ of multi-cation and single-cation AEMs as a function of $\mathrm{OH}^{-}$ concentrations in liquid water at $20^{\circ} \mathrm{C}$.

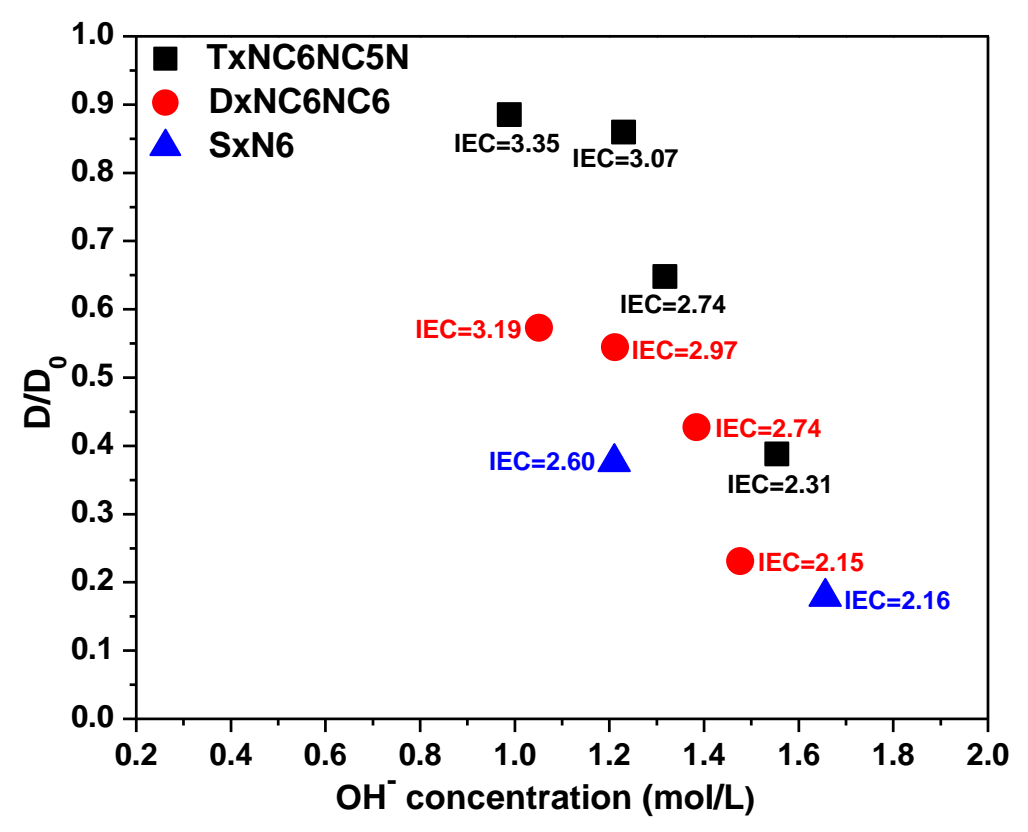

Figure $\mathrm{S} 9 . \mathrm{OH}^{-}$mobility ratios $\left(D / D_{0}\right)$ of multi-cation and single-cation AEMs as a function of $\mathrm{OH}^{-}$concentrations in liquid water at $20^{\circ} \mathrm{C}$. 
Figure S10 shows the ${ }^{1} \mathrm{H}$ NMR spectra of D30NC6NC6 before and after stability tests in $1 \mathrm{M}$ $\mathrm{NaOH}$ solution at $80^{\circ} \mathrm{C}$.

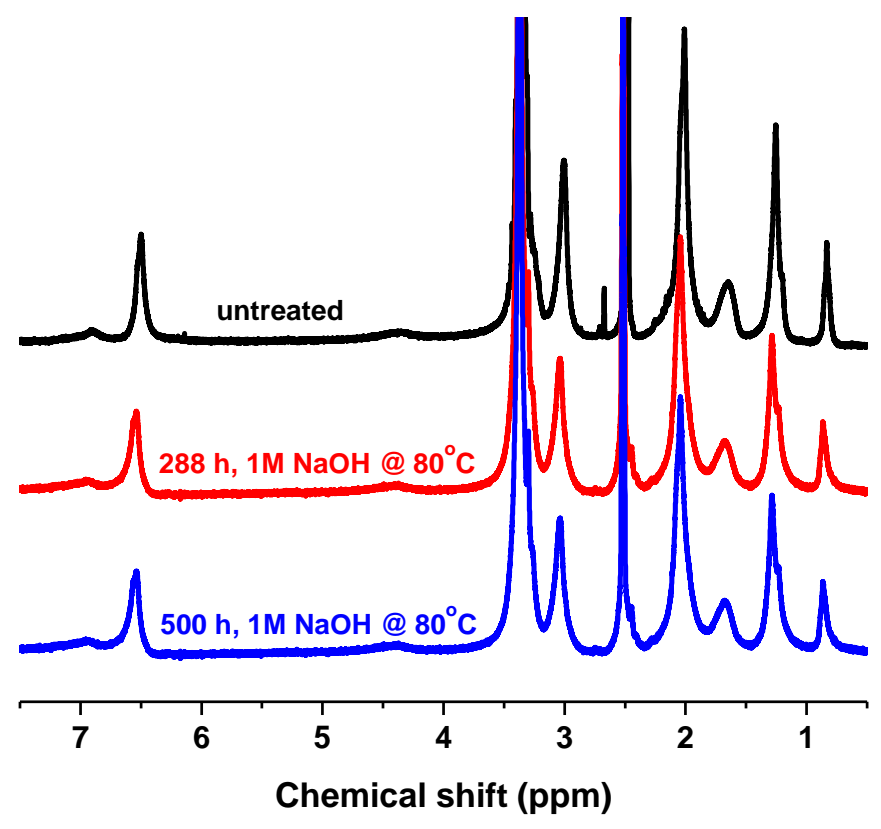

Figure S10. ${ }^{1} \mathrm{H}$ NMR spectra of D30NC6NC6 before and after stability tests in $1 \mathrm{M} \mathrm{NaOH}$ solution at $80^{\circ} \mathrm{C}$. 
Figure S11 shows the $\mathrm{OH}^{-}$conductivity measured at $20{ }^{\circ} \mathrm{C}$ for T20NC6NC5N, D30NC6NC6, S60NC6 and BTMA40 samples degraded in $4 \mathrm{M} \mathrm{NaOH}$ solution at $80{ }^{\circ} \mathrm{C}$.

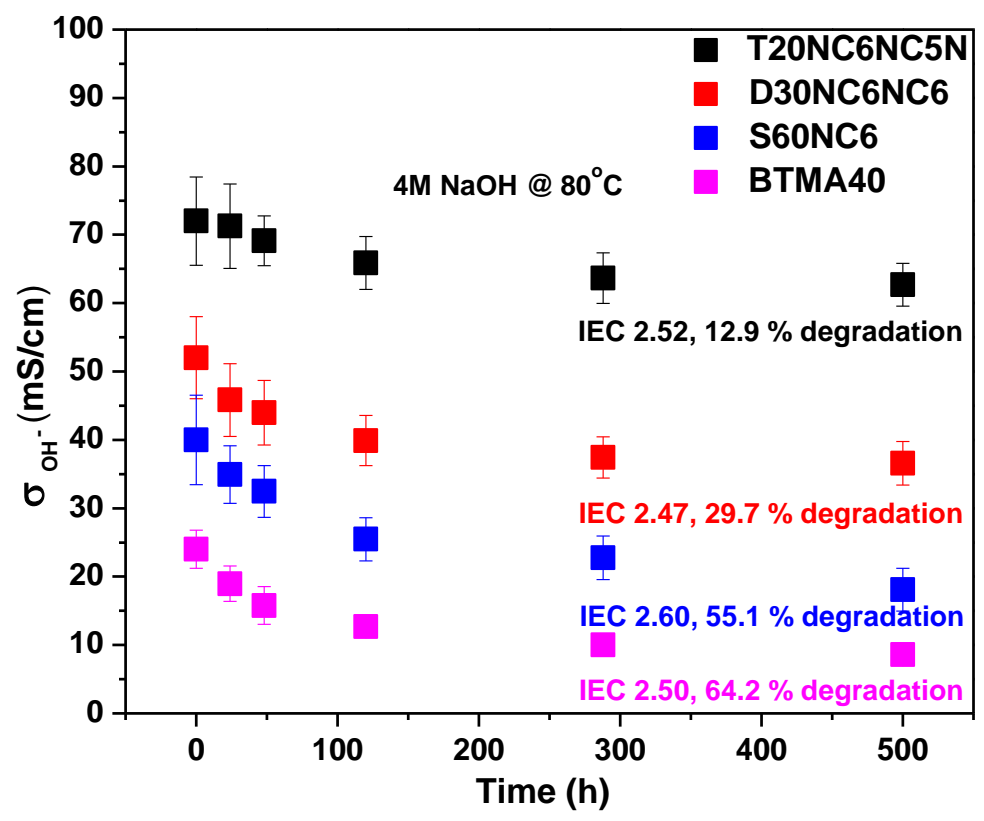

Figure S11. $\mathrm{OH}^{-}$conductivity measured at $20{ }^{\circ} \mathrm{C}$ for the T20NC6NC5N, D30NC6NC6, S60NC6 and BTMA40 samples in $4 \mathrm{M} \mathrm{NaOH}$ solution at $80{ }^{\circ} \mathrm{C}$ as a function of degradation time. 